\title{
EFFORT-REWARD BALANCE AS A MEDIATOR OF THE RELATIONSHIP BETWEEN SUPPLEMENTARY PERSON-ORGANIZATION FIT AND PERCEIVED STRESS AMONG MIDDLE-LEVEL MANAGERS
}

\section{MALGORZATA WASZKOWSKA, ALEKSANDRA JACUKOWICZ, MARCIN DRABEK, and DOROTA MERECZ-KOT}

Nofer Institute of Occupational Medicine, Łódź, Poland

Department of Health and Work Psychology

\begin{abstract}
Objectives: The study has aimed to identify the relations between the supplementary person-organization fit (P-O fit) and the perceived stress among managerial staff, with special regard to the mediating role of the effort-reward balance. Material and Methods: The study sample consisted of 715 middle-level managers, aged 25-64 years old, employed in large companies. To measure the selected variables, the authors used the Questionnaire of Effort-Reward Imbalance (ERI), Perceived Stress Scale - 10 (PSS-10), and Person-Organization Fit Questionnaire. Results: The regression analysis revealed that the perceived effort-reward imbalance partially mediated the negative relationship between the supplementary person-organization fit and stress. Conclusions: The results suggest that even when the characteristics of the manager and organization are highly congruent, the managers will experience stress if their work involves heavy effort or when this effort is not compensated properly. Int J Occup Med Environ Health 2017;30(2):305-312
\end{abstract}

Key words:

Distress, Effort-reward imbalance, Personnel management, Middle-level managers, Stress at work, Person-organization fit

\section{INTRODUCTION}

Today's managers constitute a very important group of employees who are largely responsible for the company development and success. Being a manager involves high responsibility and necessity to take difficult, sometimes unpopular, decisions.

The previous research on stress in this group focused on the psychosocial risks in their work environment [1,2]. Most of the findings indicate that the level of perceived stress among company managers was similar to that in other groups of employees but the prevalence of mental health problems was higher than it could be expected based on the level of the reported stress [2-4]. Hence, occupational stress among managers may be associated not only with the psychosocial factors that are directly related to the job performed but also to the discrepancy between individual characteristics of the employee and the company. The previous research had already confirmed that the person-organization fit (P-O fit) had constituted a significant factor that had had the impact on the quality

Funding: the project was financed with grant for statutory activity of the Nofer Institute of Occupational Medicine, Łódź, Poland, from subsidy No. IMP 21.6/2014-15 "Effort-reward imbalance as a moderator of relation between person-organization fit and stress." Project manager: Małgorzata Waszkowska, Ph.D.

Received: December 21, 2015. Accepted: March 31, 2016.

Corresponding author: M. Waszkowska, Nofer Institute of Occupational Medicine, Department of Health and Work Psychology, Psychological Diagnostics Unit, św. Teresy 8, 91-348 Łódź, Poland (e-mail: malgorzata.waszkowska@imp.lodz.pl). 
of occupational functioning. Both the supplementary fit (related to the congruity of the worker's attitudes, values, norms, goals and the organization's culture) and the complementary fit (occurring when a worker is able to satisfy the demands of the organization and his or her individual needs are also met by the organization) are positively related to job satisfaction and contextual performance [5]. However, the relationships between particular P-O dimensions, their components and various aspects of the worker's functioning are slightly different. Numerous studies indicate that the relationship found between the supplementary P-O fit and organizational commitment, intent to quit, and job satisfaction is stronger than that found for the complementary fit (needs-supplies fit) [5]. The congruence of values held by the employees and the organization induces higher organizational commitment and extra effort to work [6]. Consequently, insufficient $\mathrm{P}-\mathrm{O}$ fit relates to the intention to quit, turnover, and strain [5].

Little is known about the mechanisms linking the $\mathrm{P}-\mathrm{O}$ fit and its effects. Most researchers underline that perceived social exchange with the organization is a mechanism through which the $\mathrm{P}-\mathrm{O}$ fit influences employees and work outcomes. According to Edwards and Cable [7], the essential norms, values and goals which constitute organizations' culture and climate, state how their members should behave and how resources should be allocated. The employees, in turn, derive from these norms the guidelines on their decision-making and actions to be taken in order to fulfill their duties. In the case of a discrepancy in this respect between the employee and the organization, the rules, procedures, and devices promoted for goal achievement, that stem from the organization's culture, are perceived by the employee as limiting their actions. They may provoke negative emotional, cognitive and behavioral outcomes and are potential stressors [8].

The aforementioned authors also found strong relationships between personal values and psychological needs and organizational values and supplies. They demonstra- ted direct links between value congruence and job satisfaction, intention to stay, organizational identification as well as the mediating effect of the need for fulfillment [9]. Thus, value congruency affords the individual the opportunity to fulfill his or her needs.

Similar relationships were also confirmed by other authors. It should also be noted that the fulfillment of needs links strictly to the partner's demands and capability. Also organizational values, norms and goals determine the context of work - working conditions, work organization, methods and thus, the demands from the partner of the interaction [10]. Therefore, it may be expected that despite the value congruence between employers and employees, one might sometimes face an imbalance between the employer's demands, the employee's effort to put these demands into realization, and the fulfillment of the employee's expectations and needs, as described in Siegrist's Effort-Reward Imbalance (ERI) model [11]. Middle-level managers have an exceptionally difficult role in a company whereas their capacity to control the general strategy and goals of the company, its policy, and organizational culture is limited. Nevertheless, these aspects largely determine the way they perform their own tasks and manage subordinate organizational units regardless of their own preferences. Thus, it may be expected that a high supplementary P-O fit (S P-O fit) enhances the psychological well-being at work whereas the discrepancy between a manager and an organization in this context is a potential source of distress. Moreover, the managers' engagement in work may be disproportionate to the resources that the organization may offer them. Meeting these high job demands requires substantial effort on the part of the managerial staff. At the same time, they expect that their activity will be appreciated by the employers, which will be reflected in good salary, esteem, career development and job security. If an employee's effort is high and disproportionate to the achieved rewards, it becomes a source of stress and severe health consequences [12]. 
Moreover, several reports indicate that the perceived reward may have a greater influence on the employee's strain than does the effort itself [11].

This study has been designed to examine the relationship between the supplementary person-organization fit among managers and the perceived stress, with special regard to the balance between effort and reward as a factor mediating this relation. We postulate that the imbalance between effort and reward has an adverse effect on well-being and it reduces the protective effect of the good P-O supplementary fit on stress.

Two hypotheses were tested:

- hypothesis 1: supplementary P-O fit relates negatively to perceived stress among managerial staff,

- hypothesis 2: effort-reward imbalance and its components mediate the relationship between the supplementary $\mathrm{P}-\mathrm{O}$ fit and stress.

We have also examined which ERI component has a higher influence on the relationship between the supplementary fit and stress.

\section{MATERIAL AND METHODS}

\section{Participants and procedure}

The study concerned a group of managers who were employed in randomly selected large enterprises (with at least 250 employees). When recruiting the participants, we paid special attention to keep the actual male to female ratio among managers in each company covered by the study.

The study sample comprised 715 middle-level managers: 381 women and 334 men. The participants were 25-64 years of age (mean $(M)=42.7 \pm 8.8$ ) and their job tenure at the current position varied from 2 years to 33 years $(\mathrm{M}=8.2 \pm 5.9)$. Most of the participants (583 persons) had master's or bachelor's degree, 127 had college education and 5 basic vocational education. The data was collected during their working hours. All subjects were informed that the study was confidential and anonymous and its results would be used only for research purposes. They completed a questionnaire regarding their socio-demographic characteristics as well as questionnaires measuring the psychological variables.

\section{Measures \\ Supplementary Person-Organization Fit Questionnaire by Czarnota-Bojarska}

To measure a subjective supplementary person-organization fit, we used one of the scales from the $\mathrm{P}-\mathrm{O}$ fit questionnaire developed by Czarnota-Bojarska [13]. The whole questionnaire included 50 items, 16 of them referring to the supplementary P-O fit.

The respondents were asked to indicate to what extent they agreed with the statements using a 6-point response scale from "I definitely disagree" to "I definitely agree." In order to determine the indices of the supplementary $\mathrm{P}-\mathrm{O}$ fit, we calculated the mean values for the scores (the results ranged 1-6). The higher the score, the better the person-organization fit. The subscale for the S P-O fit showed high level of internal reliability. In our study, Cronbach's $\alpha$ equaled 0.97 .

Questionnaire on Effort-Reward Imbalance (ERI)

by Siegrist

To measure the imbalance between the effort put into one's work and the obtained reward, we used a Polish adaptation of Siegrist's 17-item ERI questionnaire developed by Widerszal-Bazyl et al. [14]. The effort scale included 6 items describing various job demands such as time pressure, distractors or responsibility. The reward scale included 11 items referring to financial or esteem rewards, job security, etc. The respondents were to indicate whether a particular situation described in an item applied to their job and whether it was a source of stress to them, by selecting one option from a scale ranging from "No" to "Yes, and it disturbs me a lot." The mean values in each scale served as indices of the Effort-Reward (they 
ranged 1-5). The Effort-Reward ratio was calculated using the formula developed by Siegrist et al. [15].

Internal reliability measured with Cronbach's $\alpha$ was satisfactory for both scales and equaled 0.75 for the Effort scale and 0.79 for the Reward scale [16]. For our study sample, these indices amounted to 0.7 and 0.87 , respectively.

\section{PSS-10 by Cohen, Kamarck and Mermelstein}

The subjective sense of stress was calculated using a Polish version of the Perceived Stress Scale - 10 (PSS-10) questionnaire (the original version by Cohen, Kamarck and Mermelstein [17]) adapted by Juczyński and OgińskaBulik [18]. The questionnaire included 10 items related to a person's experience of stressful events, and one's ability to cope with them within a period of 1 month prior to the examination. The respondents' task was to indicate how often they had experienced the described states, using a 5 -point scale from 0 - never, to 4 - very often. To estimate the index of stress, we calculated the means of the score. The internal reliability of the test was satisfactory - Cronbach's $\alpha 0.86$ [18].

\section{Statistical analysis}

The statistical analysis was conducted using SPSS 23 software. We calculated the means, standard deviations and Spearman's rank correlations for all the study variables.
To verify the hypothesis about the mediating role of the ERI on the relationship between the supplementary P-O fit and perceived stress, we used the concept adopted by Baron and Kenny [19]. We also conducted a series of linear regression analyses to assess the relationships between the S P-O fit and stress. We used effort, reward, and Effort-Reward ratio as the mediating variables. When a partial mediation occurred, we also conducted Sobel's test to determine the significance of the difference between $\beta$ coefficients for each factor.

\section{RESULTS}

All the study variables were intercorrelated at the level of significance at $\mathrm{p}<0.001$, thus the data met the criteria for performing linear regression analyses (Table 1). As expected, the S P-O fit and rewards correlated negatively with stress. Effort and the Effort-Reward ratio were positively related to stress. Moreover, the S P-O fit was also positively associated with reward and negatively with the ER ratio (imbalance).

The Table 2 presents the results of the analysis of the mediating role of the ERI components on the relationship between the supplementary $\mathrm{P}-\mathrm{O}$ fit and perceived stress.

The Block I shows the regression model including the supplementary P-O fit as independent variables and

Table 1. Descriptive statistics and correlations between supplementary person-organization fit and perceived stress and effort-reward balance among managerial staff

\begin{tabular}{lrrrrr}
\hline \multicolumn{1}{c}{ Variable } & \multirow{2}{*}{$\mathrm{M} \pm \mathrm{SD}$} & \multicolumn{4}{c}{ Spearman's rank correlations* } \\
\cline { 3 - 6 } & & 1 & 2 & 3 & 4 \\
\hline 1. Supplementary person-organization fit & $4.77 \pm 0.65$ & & & & \\
2. Stress & $1.63 \pm 0.64$ & -0.41 & & & \\
3. Effort & $2.30 \pm 0.84$ & -0.12 & -0.30 & & \\
4. Reward & $4.34 \pm 0.81$ & 0.51 & -0.35 & -0.30 & \\
5. Effort-Reward ratio & $0.59 \pm 0.44$ & -0.28 & 0.38 & 0.93 & -0.56 \\
\hline
\end{tabular}

$\mathrm{M}$ - mean; SD - standard deviation.

$* \mathrm{p}<0.001$. 
Table 2. Mediating role of Effort-Reward Imbalance (ERI) components on the relationship between supplementary person-organization fit and perceived stress among middle-level managers*

\begin{tabular}{|c|c|c|c|c|c|}
\hline Block and predictor & $\begin{array}{l}\text { Dependent } \\
\text { variable }\end{array}$ & $\mathrm{B} \pm \mathrm{SE}$ & $\beta$ & $\begin{array}{c}\text { Explained } \\
\text { variation } \\
{[\%]}\end{array}$ & $\mathrm{F}$ \\
\hline \multicolumn{6}{|l|}{ I. Mediator - ERI-Effort } \\
\hline supplementary person-organization fit & effort & $-0.22 \pm 0.05$ & -0.17 & 3 & 21.52 \\
\hline effort & stress & $0.25 \pm 0.03$ & 0.32 & 10 & 82.02 \\
\hline $\begin{array}{l}\text { supplementary person-organization fit } \\
\text { mediation effect }\end{array}$ & stress & $-0.42 \pm 0.03$ & -0.42 & 19 & 154.37 \\
\hline $\begin{array}{l}\text { supplementary person-organization fit } \\
\text { effort }\end{array}$ & stress & $\begin{array}{r}-0.38 \pm 0.03 \\
0.20 \pm 0.03\end{array}$ & $\begin{array}{l}-0.38 \\
-0.26\end{array}$ & 24 & 113.56 \\
\hline \multicolumn{6}{|l|}{ II. Mediator - ERI-Reward } \\
\hline supplementary person-organization fit & reward & $0.75 \pm 0.04$ & 0.60 & 36 & 394.33 \\
\hline reward & stress & $-0.32 \pm 0.03$ & -0.41 & 17 & 142.24 \\
\hline $\begin{array}{l}\text { supplementary person-organization fit } \\
\text { mediation effect }\end{array}$ & stress & $-0.42 \pm 0.03$ & -0.42 & 19 & 154.37 \\
\hline $\begin{array}{l}\text { supplementary person-organization fit } \\
\text { reward }\end{array}$ & stress & $\begin{array}{l}-0.28 \pm 0.04 \\
-0.19 \pm 0.03\end{array}$ & $\begin{array}{l}-0.28 \\
-0.24\end{array}$ & 22 & 97.97 \\
\hline \multicolumn{6}{|l|}{ III. Mediator - ERI-Ratio } \\
\hline supplementary person-organization fit & $\begin{array}{l}\text { effort-reward } \\
\text { ratio }\end{array}$ & $-0.29 \pm 0.02$ & -0.43 & 19 & 162.38 \\
\hline Effort-and-Reward ratio & stress & $0.54 \pm 0.05$ & 0.37 & 14 & 114.69 \\
\hline $\begin{array}{l}\text { supplementary person-organization fit } \\
\text { mediation effect }\end{array}$ & stress & $-0.42 \pm 0.03$ & -0.42 & 19 & 154.37 \\
\hline supplementary person-organization fit & stress & $-0.32 \pm 0.04$ & -0.32 & 22 & 101.91 \\
\hline Effort-Reward ratio & & $-0.34 \pm 0.05$ & 0.23 & & \\
\hline
\end{tabular}

$* \mathrm{p}<0.001$.

$\mathrm{B}$ - non standardized regression coefficient; SE - standard error; $\beta$ - standardized regression coefficient; F - Fisher statistics.

the ERI-Effort included as a variable mediating the relationship between the S P-O fit and perceived stress.

When analyzed separately, the S P-O fit and the ERIEffort were significantly related to stress. When both of them were included into the regression model, the strength of the relationship between the S P-O fit and stress was found to decrease $(\beta=-0.42, p<0.001$ to $\beta=-0.38, p<0.001)$. However, it was still a significant predictor, which meant that a partial mediation occurred. The change was significant, which was confirmed by Sobel's test $(\mathrm{Z}=-3.96, \mathrm{p}<0.001)$. Both the variables explained $24 \%$ of variance, i.e., more than they explained separately.

Similar analyses were conducted for the ERI-Reward as a mediator (Table 2, block II). This variable changed the strength of the relationship between the S P-O fit $(\beta=-0.42, p<0.05$ to $\beta=-0.28, p<0.05, Z=-5.61$, $\mathrm{p}<0.001)$ and perceived stress. Thus, reward showed significant influence on this relationship but it was a partial mediator, just as the effort. We also tested the hypothesis 
on the mediating role of the Effort-Reward imbalance on the relationship between the supplementary fit and perceived stress (Table 2, block III). The Effort-Reward imbalance ratio appeared to be a significant predictor of stress perceived by the managers. The strength of the relationship between the supplementary P-O fit and perceived stress decreased when we introduced the ERI-ratio into the model $(\beta=-0.42, \mathrm{p}<0.05$ to $\beta=-0.32, \mathrm{p}<0.05)$. Thus, we may conclude that the ERI-ratio is a partial mediator of this relationship, which was also confirmed by Sobel's test $(\mathrm{Z}=-5.7, \mathrm{p}<0.001)$. The $\mathrm{S} \mathrm{P}-\mathrm{O}$ fit and ERIratio explained $22 \%$ of the stress variance.

\section{DISCUSSION}

This study has aimed to investigate the impact of effort, reward and their ratio on the relationship between the supplementary P-O fit and the level of stress among middle-level managerial staff.

The results showed that this type of fit was negatively related to the perceived stress. The lower the congruence of the values, goals and expectations shared by the managers and their organizations, the stronger the experienced stress. This outcome confirmed our earlier assumptions and was consistent with other findings [20,21].

The strength of the relationship between the S P-O fit and the perceived stress was found to be moderate. However; it still seems pertinent considering that:

- the managerial staff is usually carefully selected in the companies; thus, the discrepancy between their characteristics and the company's features is less likely to occur [22];

- work environment offers the managers a variety of resources (e.g., higher degree of freedom, possibilities for development), which may diminish the influence of stressors and help them cope with the stressors more effectively [2].

In this study, the relationship between the supplementary $\mathrm{P}-\mathrm{O}$ fit and stress among managers was modified by the imbalance between effort expanded at work and received rewards. The greater the discrepancy between the manager's and organization's characteristics and the higher ERI, the higher the level of experienced stress.

We also discovered a similar impact of effort and reward on the referred relationship when these variables were analyzed separately. It should be emphasized that these effects are only partial; thus, our hypotheses have not been fully confirmed. Nevertheless, our results are supported by the findings from the study by Kim et al. [23] who demonstrated a mediating effect of the perceived social exchange with organization on the relationship between the $\mathrm{P}-\mathrm{O}$ fit and the outcomes obtained by employees.

Importantly, in our study the managers achieved a lot higher mean results in the Reward scale in comparison to their scores in the Effort scale. There was also a stronger positive correlation between this scale and the supplementary fit. Such result might suggest that the values, goals and organizational climate preferred by the company translate into the human resources policy to a greater extent (for instance, the distribution and amount of remuneration, promotion possibilities) than the demands imposed on managers. It might be also suspected that managers perceive the concurrence of the organization's and their own characteristics mainly through the lens of the benefits they reap from their work. The explanation of the issue exceeds the scope of our studies, yet, it might become an inspiration for further research in this area.

To our knowledge, this is the 1st report on the role of the effort and reward balance as a factor mediating the relationship between the $\mathrm{P}-\mathrm{O}$ fit and stress.

Our findings should be interpreted with caution as the study contained a few limitations. First, it was an exploratory, cross-sectional study; thus the results referred only to a short-time perspective.

Second, we used the PSS-10 questionnaire as an indicator of stress. The scale is used for measuring general stress, which may be related both to work and private life. 
Therefore, the discussed effects of the S P-O fit, effort, reward and their ratio may have been stronger if the occupational stress had been the only type of stress measured in the study.

Third, the results of this study cannot be generalized and interpreted in reference to the whole population of workers. The employee-organization relationship depends on the organization's characteristics, employee's position in the company's structure and his or her role [24,25].

\section{CONCLUSIONS}

Our findings suggest that even when the characteristics of the manager and organization are highly congruent, the managers will experience stress if their work involves heavy effort or when this effort is not compensated properly. This implies that companies should have a personnel policy that will not only provide the company with a highly-motivated staff but will also adequately compensate the staff for their commitment.

\section{REFERENCES}

1. Lindorff M. Are they lonely at the top? Social relationships and social support among Australian managers. Work Stress. 2001;15(3):274-82, https://doi.org/10.1080/026783701110.108 0/02678370110066599.

2. Skakon J, Kristensen TS, Christensen KB, Lund T, Labriola M. Do managers experience more stress than employees? Results from the Intervention Project on Absence and Well-being (IPAW) study among Danish managers and their employees. Work. 2011;38(2):103-9, https://doi.org/10.3233/WOR-2011-1112.

3. Ogińska-Bulik N. [Occupational stress in social service occupations. Sources - Consequences - Prevention]. Warszawa: Difin; 2006. Polish.

4. Steptoe A, Willemsen G. The influence of low job control on ambulatory blood pressure and perceived stress over the working day in men and women from the Whitehall II cohort. J Hypertens. 2004;22(5):915-20, https://doi. org/10.1097/00004872-200405000-00012.
5. Kristof-Brown AL, Zimmerman RD, Johnson EC. Consequences of individuals' fit at work: A meta-analysis of person-job, person-organization, person-group, and personsupervisor fit. Pers Psychol. 2005;58(2):281-342, https://doi. org/10.1111/j.1744-6570.2005.00672.x.

6. Huang MP, Cheng BS, Chou LF. Fitting in organizational values: The mediating role of person-organization fit between CEO charismatic leadership and employee outcomes. Int J Manpow. 2005;26(1):35-49, https://doi. org/10.1108/01437720510587262.

7. Edwards JR, Cable DM. The value of value congruence. J Appl Psychol. 2009;94(3):654-77, https://doi.org/10.1037/ a0014891.

8. Nixon A, Mazzola J, Bauer J, Krueger J, Spector P. Can work make you sick? A meta-analysis of the relationships between job stressors and physical symptoms. Work Stress. 2011;25(1):1-22, https://doi.org/10.1080/02678373.2011. 569175.

9. Cable DM, Edwards JR. Complementary and suplementary fit: A theoretical and empirical integration. J Appl Psychol. 2004;89(5):822-34, https://doi.org/10.1037/0021-9010. 89.5.822.

10. Lovelace K, Rosen B. Differences in achieving person-organization fit among diverse groups of managers. J Manage. 1996;22(5):703-22, https://doi.org/10.1177/01492063960 2200502.

11. Allisey A, Rodwell J, Noblet A. Personality and the effortreward imbalance of stress: Individual differences in reward sensitivity. Work Stress. 2012;26(3):230-51, https://doi.org/ 10.1080/02678373.2012.714535.

12. Niedhammer I, Tek ML, Starke D, Siegrist J. Effort-reward imbalance model and self-reported health: Cross-sectional and prospective findings from the GAZEL cohort. Soc Sci Med. 2004;58(8):1531-41, https://doi.org/10.1016/S0277-95 36(03)00346-0.

13. Czarnota-Bojarska J. [Person-organization fit and organizational identity]. Warszawa: Wydawnictwo Naukowe Scholar; 2010. Polish. 
14. Widerszal-Bazyl M, Radkiewicz P, Pokorski J, Pokorska J, Ogińska H, Pietsch E. Who wants to leave nursing in Poland? In: Hasselhorn H-M, Tackenberg P, Muller BH, editors. Working conditions and intent to leave the profession among nursing staff in Europe. Report No. 7. Stockholm: National Institute for Working Life; 2003. p. 203-13.

15. Siegrist J, Li J, Montano D. Psychometric properties of the Effort-Reward Imbalance Questionnaire [Internet]. Duesseldorf: Duesseldorf University; 2014 [cited 2015 Nov 2]. Available from: http://www.uniklinik-duesseldorf.de/fileadmin/Datenpool/einrichtungen/institut_fuer_medizinische_ soziologie_id54/ERI/PsychometricProperties.pdf.

16. Kuemmerling A, Hasselhorn H-M, Tackenberg P. Psychometric properties of the scales used in the NEXT-Study. In: Hasselhorn H-M, Tackenberg P, Muller BH, editors. Working conditions and intent to leave the profession among nursing staff in Europe. Report No 7. Stockholm: National Institute for Working Life; 2003. p. 237-57.

17. Cohen S, Kamarck T, Mermelstein R. A global measure of perceived stress. J Health Soc Behav. 1983;24:385-96.

18. Juczyński Z, Ogińska-Bulik N. [Tools to measure stress and coping with stress]. Warszawa: Pracownia Testów Psychologicznych; 2009. Polish.

19. Baron RM, Kenny DA. The moderator-mediator variable distinction in social psychological research: Conceptual, strategic, and statistical considerations. J Pers Soc Psychol. 1986;51(6):1173-82, https://doi.org/10.1037/0022-3514. 51.6.1173.

20. Bocchino CC, Hartman BW, Foley PF. The relationship between person-organization congruence, perceived violations of the psychological contract, and occupational stress symptoms. Consult Psychol J. 2003;55(4):203-14, https://doi. org/10.1037/1061-4087.55.4.203.

21. Pithers RT, Soden R. Person-environment fit and teacher stress. Educ Res. 1999;41(1):51-61, https://doi.org/10. 1080/0013188990410105.

22. Khalid K, Ahyat MS, Bustaman HA. The cost of person organization fit. Int J Acad Res. 2012;4(2):63-6.

23. Kim T-Y, Aryee S, Loi R, Kim S-P. Person-organization fit and employee outcomes: Test of a social exchange model. Int J Hum Resour Manage. 2013;24(19):3719-37, https://doi.org/ 10.1080/09585192.2013.781522.

24. Lu C, Siu O, Au W, Leung S. Manager's occupational stress in state-owned and private enterprises in the People's Republic of China. Int J Hum Resour Manage. 2009;20(8):1670-82, https://doi.org/10.1080/09585190903087024.

25. Widerszal-Bazyl M, Cooper CL, Sarks K, Sector PE. Managerial stress in private and state organisations in Poland. Stress Health.2000;16(5):299-314,https://doi.org/10.1002/10991700(200010)16:5<299::AID-SMI874>3.0.CO;2-K.

This work is available in Open Access model and licensed under a Creative Commons Attribution-NonCommercial 3.0 Poland License - http://creativecommons.org/ licenses/by-nc/3.0/pl/deed.en. 